\title{
Application of Superconducting Fault Current Limiter (SFCL) in Power Systems: A Review
}

\author{
I. K. Okakwu, P. E. Orukpe and E. A. Ogujor
}

\begin{abstract}
The fault current levels of an interconnected power network have witnessed a general rise due to increase in power demand. This rise in fault current if not properly mitigated may exceed the maximum ratings of the switchgear. Many conventional protective devices such as series reactors, fuses, high impedance transformers, etc. have high cost, increased power loss and loss of power system stability, which may ultimately cause lower reliability and reduced operational flexibility. Superconducting Fault Current Limiter (SFCL) is a flexible alternative to the use of conventional protective devices, due to its effective ways of reducing fault current within the first cycle of fault current, reduced weight and zero impedance during normal operation. This paper reviews various concepts of SFCLs and its applications in power systems.
\end{abstract}

Index Terms-Fault Current; Low Temperature Superconductor; Power Systems; Superconducting Fault Current Limiter.

\section{INTRODUCTION}

Since every nation yearns for increase in power generation in order to meet its ever increasing population demand for energy, this increase in generation has made the interconnected power system network more complex [1]. The complexity of a power system is directly proportional to its fault current level. This increase in fault current due to the complexity of a power system network has become a major threat to the smooth operation and control of power systems [2]; thus limiting this fault current has become necessary since switchgear equipment like transformers, circuit breakers etc. has already been sized and installed before the complexity of the interconnection network [3]. So many conventional means had been suggested in the past for curtailing fault current, which includes: system reconfiguration, upgrading the circuit breakers, using transformers of higher impedance, sequential breaker tripping, fuses, air-core reactors, etc. [4], [5]. However, the use of these conventional devices poses challenges ranging from high cost, increase in power losses, lack of system security and reliability [6].

Superconducting Fault Current Limiter (SFCL) is a viable alternative to the use of conventional means of reducing fault current [7]. Superconducting fault current limiter has the capability to reduce fault current within the first cycle of fault current and has zero impedance during normal operation and large impedance during fault condition which can limit fault current within a predefined value during a transient condition [8]. In the event of a fault, SFCL will lose its superconductivity nature and introduce amount of impedance into the circuit where it is connected [9]. The SFCL does not only suppress fault current but also enhances the power system stability.

This paper presents the theoretical background and up-todate literature review on SFCL applications in power systems.

\section{SUPERCONDUCTING FAULT CURRENT LIMITER}

A Nobel Laureate Dutch Scientist named Kamerlingh Onnes, in 1911 discovered that the resistance of mercury disappeared as the temperature drops below certain critical values [10]. This phenomenon was termed as superconductivity of mercury. Later, research also went further to show that many other components or materials also exhibit these same superconductivity properties with their own critical temperature [11]. The current limiting characteristics of SFCL depend on its nonlinear response to temperature (T), magnetic field (B) and current density (J) [12], as shown in Fig. 1.

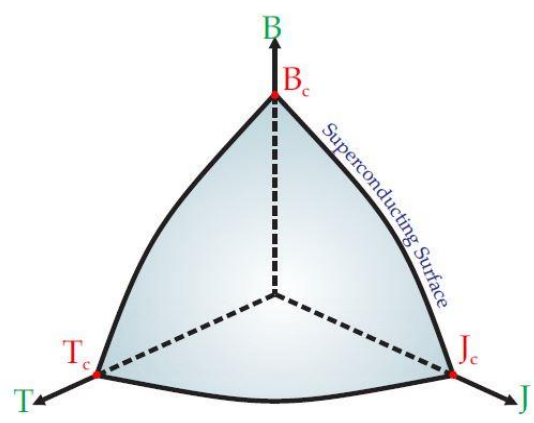

Fig. 1. T-B-J Characteristics of Superconductor Material [13]

The superconductivity of a superconductor material will be destroyed when the superconducting material is exposed beyond a certain temperature, magnetic field and current density called critical values [14]. Below these critical values, it has a negligible resistance and this implies that it is in its superconducting mode, and above these critical values it has high resistance and is said to be in its current limiting state [15]. Therefore, increasing any of these three parameters beyond their critical limit will cause the conducting material to lose its superconducting property [16]. The SFCL uses its variable resistance nature during fault to limit the fault current as shown in Fig. 2. 


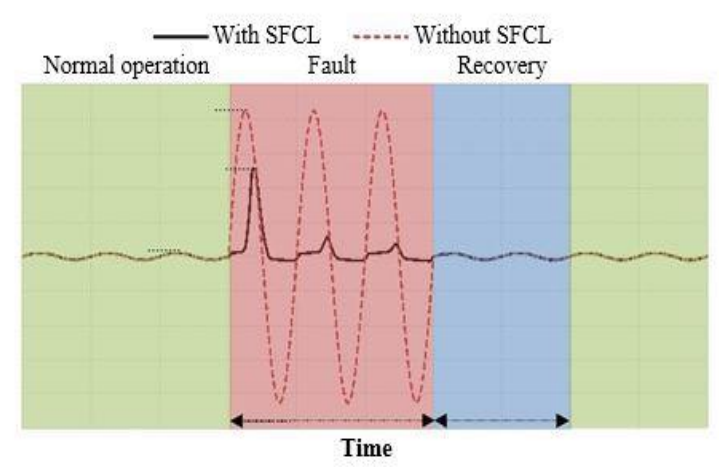

Fig. 2. The current waveform with and without SFCL [17]

An SFCL helps to manage economically this fault current to avoid damages to equipment which can result in blackouts.

Superconductor fault current limiter does not suppress the fault current completely, but rather reduces the fault current to a level that the equipment or devices can withstand [18]. There are seven types of superconducting fault current limiters and a detailed explanation of each is presented in section 3 of [9].

Superconductors are classified into two types, namely; Low Temperature Superconductor (LTS) and High Temperature Superconductor (HTS). The LTS are the first generation (1G) superconductors having a transition temperature below 25K [19]. SFCL based on LTS are not commercialized because of their low operating temperature that requires a high cost cooling system (the material is cooled using liquid Helium). At present, LTS materials have been replaced with High Temperature Superconductor (HTS) materials. HTS is a second generation (2G) superconductor [6] which is cost effective particularly at high temperatures. The critical temperature of HTS is up to $110 \mathrm{~K}$. Fault current limiters utilizing HTS are often cooled using liquid nitrogen [20]. The two most important HTS used industrially as a coated conductor are Yittrium-BariumCopper-Oxide (YBCO) and Bismut-Strontium-CalciumCopper-Oxide (BSCCO with trademark of compound Bi2212/Bi-2223) [21]. YBCO belongs to a family of crystalline chemical compounds having a generalized formula of $\mathrm{YBa}_{2} \mathrm{Cu}_{3} \mathrm{O}_{7-\mathrm{x}}$, with a critical temperature of $93 \mathrm{~K}$ [22]. YBCO is produced either in thin film or as coated conductors by American Superconductor Corporation [23]. BSCCO belong to a family of HTS materials with a general formula of $\mathrm{Bi}_{2} \mathrm{Sr}_{2} \mathrm{Ca}_{n-1} \mathrm{Cu}_{n} \mathrm{O}_{2 n+4+x}$, with a critical temperature of $105 \mathrm{~K}$ [24]. SFCL is an ideal fault current limiter which is still being researched into and has been applied in some countries of the world [5],[9].

\section{A. Superconducting Fault Current Limiter types}

Superconductor fault current limiters are basically classified into two major types: Resistive-type SFCL and Inductive-type SFCL.

a. Resistive-type SFCL (R-SFCL): is connected in series with the network to be protected [9]. Under normal operating condition, the R-SFCL is in its superconducting state and passes the normal current without any losses. If the current increases beyond the critical current due to the occurrence of a fault, the superconducting material transits to a conducting state and introduces a resistance in series to reduce the fault current [25]. A resistor is connected in parallel with the superconducting material in order to avoid hot spots during quenching, to adjust the limiting current and avoid over-voltage due to the fast current limitations [26]. The main advantage of R-SFCL lies on its simple design, compact size and lightness when compared with the Inductive-Type SFCL. Fig. 3 shows the structure of the R-SFCL.

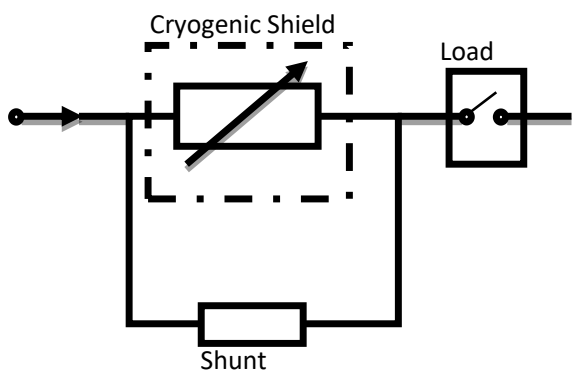

Fig. 3. Structure of R-SFCL [27]

b. Inductive-type SFCL (I-SFCL): is a special transformer connected in series with the network to be protected [27]. This transformer has a conventional primary coil (copper winding) and a special secondary winding made of HTS ring [28]. Under normal operating condition, the HTS ring prevents magnetic flux from penetrating the iron core; hence, the SFCL exhibits low impedance [29]. During fault when the current increases above the critical current, the HTS ring quenches, the secondary now becomes resistive and so the inductance of the device rises [30]. In this case, the SFCL represents high impedance.

The advantage of I-SFCL over R-SFCL is that the cryogenic power load is lesser because no heat ingress is caused through current leads into the superconductor [31]. Its disadvantages include significant losses, larger size and weight. Fig. 4 depicts the structure of I-SFCL.

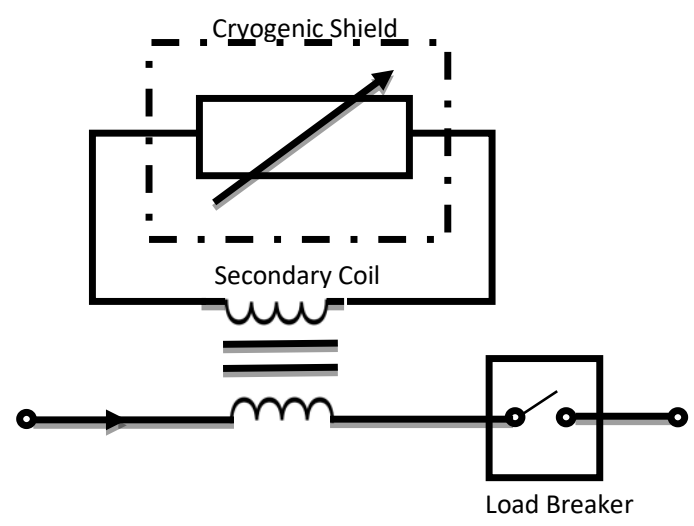

Fig. 4. Structure of I-SFCL [27]

\section{APPLICATIONS OF SFCLS IN POWER NETWORK}

The occurrence of fault in any part of a power network comprising of generation, transmission and distribution cannot be completely avoided [32]. Therefore, SFCL should be deployed in any part of the network.

Fig. 5 shows possible locations of SFCL. The location of SFCL varies significantly to effectively limit the fault 
current as well as maintaining system stability in the network.

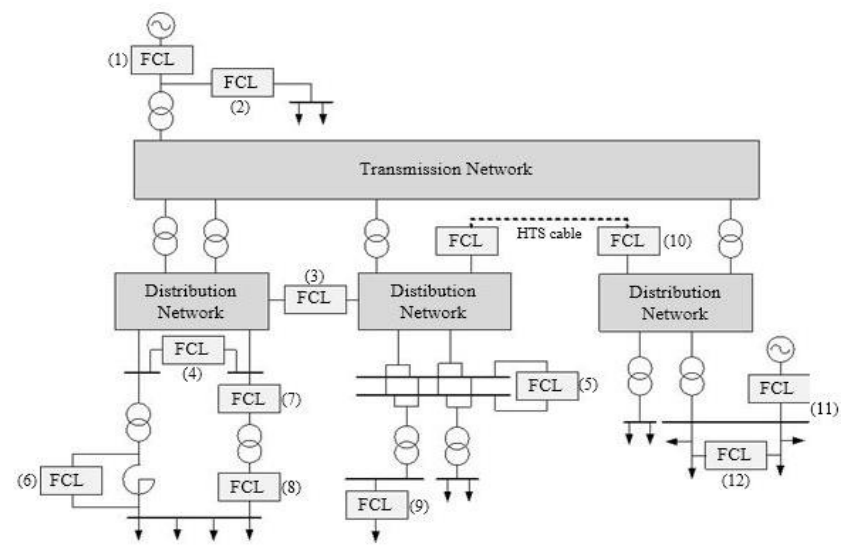

Fig. 5. Possible locations of SFCLs in a Power Network [33]

Superconducting fault current limiters (SFCLs) have been applied to transmission lines, distributed generation, renewable energy, distribution networks and HVDC systems in order to limit fault current, secure interconnector to network, reduce voltage sage at distribution, improve transient stability and reliability of the power system.

\section{LITERATURE REVIEW}

The SFCL has a unique behavior inherited from its superconducting nature, due to its nonlinear characteristics. Different studies have been carried out on the use of SFCL in improving the performance of a power system network [34]; with each focusing on different aspects of performance assessment with a view to enhancing the network. In [35], [36], the authors did a comparative study of the use of RSFCL and I-SFCL with YBCO and Bi-2212 superconducting materials on the transient stability enhancement of a multi-machine power system. Their result showed that the R-SFCL performed better than I-SFCL due to its pure resistive nature. Also, the one with YBCO superconductor material display better performance than the one of Bi-2212 for both types of SFCLs. Similarly, the authors in [37] were concerned with how the locations of RSFCL and I-SFCL will affect the transient stability of a power system network. The outcome of their study is as follows: R-SFCL is a better choice than I-SFCL, locations do not have any effect on R-SFCL and I-SFCLs are better located in line feeders. The authors in [38] were of the view that optimal sizing and allocation of R-SFCL will give a better performance to the security of the network. Their result further shows that the optimal location of the device is to some extent close to the location of fault. In [39], the authors investigated the use of I-SFCL for transient stability enhancement of the Nigeria $330 \mathrm{kV}$ transmission network. Their result reveals that the swing curve of the most severely disturbed generator was improved when I-SFCL was incorporated. The authors in [40] presented the electrical and magnetic characteristics of YBCO and BSSCO HTS tapes to be used for fault current limiter application. The result shows that YBCO tapes showed remarkable performance when compared with BSCCO tapes. The incorporation of SFCL in micro-grid system to enhance protection coordination was investigated in [41]. The result proves the effectiveness of the proposed SFCL for better relay coordination for different fault conditions. The study to improve the reliability of a Wind Turbine Generation System (WTGS) during fault using SFCL was done in. [42]. The result reveals the effectiveness of SFCL in mitigating the fault current magnitude. Investigation into the use of SFCL in improving the transient stability of a power system was carried out in [43]. The SFCL model was designed using Simulink. The result proves the effectiveness of SFCL. A method for optimum determination of the resistive value of an R-SFCL for transient stability enhancement was carried out in [44]. Minimizing kinetic energy of rotor through direct search method was adopted. The effectiveness of the proposed model was demonstrated via kinetic energy of the rotating masses at different cases using eigenvalue analysis to optimally size the resistive value of R-SFCL in enhancing the transient stability of a power network was the focus of the work in [45].

\section{DEVELOPMENT Status OF SFCL}

At the moment, several SFCLs have been developed, tested and installed across the globe. Table I depicts different HTS materials used for FCLs, while Fig. 6 and 7 shows the locations of different installation of SFCL at different sub-stations.

TABLE I: SUMMARY OF HTS MATERIALS USED FOR FCLS

\begin{tabular}{llll}
\hline \hline Institution & Country & $\begin{array}{l}\text { Power } \\
\text { Rating }\end{array}$ & $\begin{array}{l}\text { HTS } \\
\text { material }\end{array}$ \\
\hline Hydro-Quebec & Canada & 100kVA & Bi-2212 \\
ABB & Switzerland & $1.2 \mathrm{MVA}$ & Bi-2212 \\
CRIEPI & Japan & $66 \mathrm{KV}, 1 \mathrm{KA}$ & BI-2212 \\
$\begin{array}{l}\text { Nagoya } \\
\text { University }\end{array}$ & Japan & 2MVA & YBCO \\
Bruker & Germany & $40 \mathrm{MVA}$ & YBCO \\
IEL & Poland & $6 \mathrm{KV}, 0.6 \mathrm{KA}$ & YBCO \\
\hline \hline
\end{tabular}

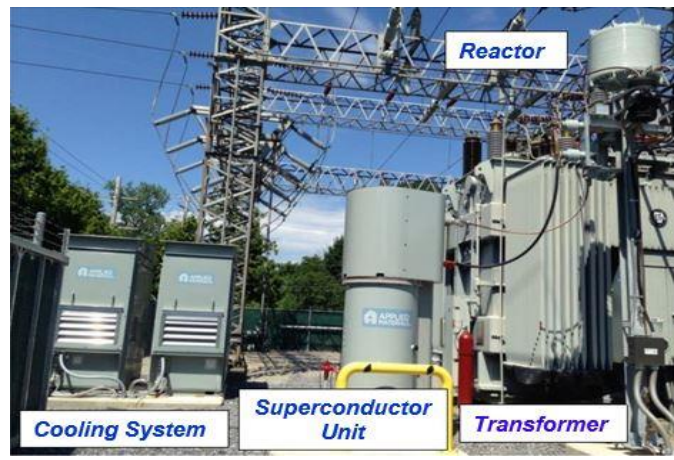

Fig. 6. Silicon Valley power, Santa Clara, California 


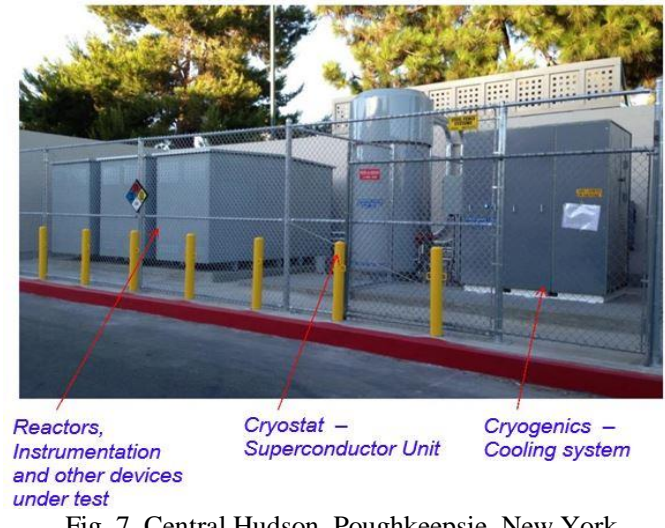

Fig. 7. Central Hudson, Poughkeepsie, New York

\section{Challenges OF IMPLEMENTING SFCLS}

There are quite a number of technical challenges which must be addressed before the installation of SFCL in a power system network. These challenges are as follows:

(a) Topology: The necessity for the installation of SFCL varies significantly for different locations. For instance, stringent time recovery should be given to the SFCL installed to protect the generator than those installed to protect a bus with an alternate feeder. Therefore, SFCL must be selected based on applications.

(b) Locations: In order to achieve maximum benefit for the installed SFCL, optimum location should be carefully determined. Hence, the best location that will give optimum benefit needs to be determined.

(c) Sizing of Impedance: The higher the impedance value of a SFCL, the better the performance during shortcircuit fault. The impedance of a SFCL is a strong pointer to the cost of SFCL. The impedance is directly proportional to cost. Hence, the impedance value needs to be optimally determined prior to its installation in the power system grid.

\section{CONCLUSION}

Due to the ever increasing load demand which has led to the expansion of an interconnected power network, which is faced with rising fault current, the use of Superconducting Fault Current Limiter has proven to be more effective than conventional fault current limiters due to its low cost, coordination with conventional equipment, less weight and effective performance. Some of the numerous benefits of SFCL in power system network are suppression of fault current on equipment during fault, reduction of voltage dips/sags and enhancement of transient stability of a power grid. In this paper, SFCL is discussed extensively and various researches on the applications of SFCL in power system were also highlighted. Finally, this paper concludes that SFCLs are anticipated solution to the numerous problems of high fault currents confronting the power grid.

\section{REFERENCES}

[1] H. Singh, and P. Jindal, "Enhancement of multi-machine stability using Fault Current Limiter and Thyristor Controlled Braking Resistor," International Journal of Modern Computer Science, vol. 4, pp. 28-31, 2016.
[2] N. Zhou, J. Wu, and Q. Wang, "Three-phase Short-Circuit Current Calculation of Power Systems with High Penetration of VSC-Based renewable energy," Journal of Energies, vol. 11, pp. 2-25, 2018.

[3] K. Makinde, F. O. Enemuoh, O. K. Lawal, I. Umar, B. Abubakar, and M. K. Mahmood, "Performance analysis of surge current protection using Superconductors," European Scientific Journal, vol. 10, pp. 183-192, 2014.

[4] A. N. Rao, and P. R. Krishna, "The Fault level reduction in distribution system using an Active type SFCL," International Journal of Engineering and Computer Science, vol. 5, pp. $17392-$ 17396, 2016

[5] M. C. Nagarathna, V. H. Murthy, and R. Shashikumar, "A Review on Super Conducting Fault Current Limiter (SFCL) in power system," International Journal of Engineering Research and General Science, vol. 3, pp. 485-489, 2015.

[6] S. Yadar, G. K. Choudhary, and R. K. Mandal, "Review on fault current limiters," International Journal of Engineering Research and Technology, vol. 3, pp. 1595-1603, 2014.

[7] B. V. Vaishnavi, S. R. S. Angelin, D. P. Trivenishree, N. Nidha, and G. J. Sowmya, "Superconducting fault current limiter and its application," International Journal of Scientific and Engineering Research, vol. 7, pp. 126-134, 2016.

[8] A. Ramadan, "Permanent magnet fault current limiter for the power grid," $9^{\text {th }}$ International Conference on Sustainability in Energy and Buildings, ELSEVIER, pp. 768-775, 2017.

[9] M. S. Alam, M. A. Y. Abido, and I. El-Amin, "Fault current limiters in power systems: A Comprehensive Review," Journal of Energies, vol. 11, pp. 2-24, 2018.

[10] X. Zhang, H. S. Ruiz, J. Geng, and T. A. Coombs, "Optimal location and minimum number of superconducting fault current limiters for the protection of power grids," International Journal of Electrical Power and Energy Systems, vol. 87, pp. 136-143, 2017.

[11] H. Yaghoubi, "The most important magnetic levitation applications," Journal of Engineering, vol. 2013, pp. 1-19, 2013.

[12] M. Pannerselvan, P. Prakasam, and J. K. Chithra, "Implementation of an effective fault current limiter for $1.51 \mathrm{MW}$ DFIG in wing power systems," International Journal of Engineering and Technology, vol. 6, pp. 627-635, 2014.

[13] Y. Zhao, "Investigation of the Superconducting Fault current limiter applied in Electrical power system with Distributed Generations (DGs)," The University of Queensland, Australia, PhD Thesis, pp. 4157, 2016.

[14] T. Uchihashi, "Two-dimensional Superconductors with atomic-scale thickness," Superconductor Science and Technology, vol. 30, pp. 138, 2016.

[15] T. Nishihara, T. Hoshino, and M. Tomita, "Analysis of FCL effect caused by superconducting DC Cables for railway system," IOP Conference Series: Materials Science and Engineering, pp. 1-9, 2017.

[16] A. N. Aswathi, and K. T. Krishna, "Microgrid protection using superconducting fault current limiter," International Research Journal of Engineering and Technology, vol. 3, pp. 1320-1325, 2016

[17] T. B. Wescley, "Thermal-Electrical Analogy for simulations of superconducting fault current limiters," Journal of Cryogenics, vol. 62, pp. 97-109, 2014.

[18] C. Song, L. Peng, B. Roy, P. Jean-Francois, and L. Brad, "Analysis of a Switched Impedance transformer-type Non-Superconducting Fault Current Limiter," IEEE Transactions on Power Electronics, vol. 30, pp. 1925-1936, 2014.

[19] S. Yadav, G. K. Choudhary, and R. K. Mandal, "Review on fault current limiters," International Journal of Engineering Research and Technology, vol. 3, pp. 1595-1603, 2014.

[20] J. Pradhan, U. Bhunia, M. Ahammad, A. Roy, S. K. Thakur, C. Mallik, and S. Saha, "Design, fabrication and testing of HTS based current lead," Indian Journal of Cryogenics, vol. 36, pp. 1-3, 2011.

[21] A. Etxegarai, I. Zamora, G. Buigues, V. Valverde, E. Torres, and P. Eguia, "Models for fault current limiters based on superconductor materials," International Conference on Renewable Energies and Power Quality, Madrid, Spain, pp. 284-289, 2016.

[22] J. A. Demko, and R. C. Duckworth, "Cooling Configuration design considerations for long-length HTS cables," IEEE Transactions on Applied Superconductivity, vol. 19, pp. 1-5, 2009.

[23] B. Zhiming, M. Chi, C. Chuan, and P. Yuchun, "Study on the Excitation of a Bi-2223 small superconducting coil by a Pulse-Type Magnetic Flux Pump," IEEE Transactions on Applied Superconductivity, vol. 27, pp. 1-5, 2017.

[24] S. Kanungo, "Synthesis and Characterization of Gd doped BSCCO2212," MSc Thesis, Department of Physics, National Institute of Technology, Rourkela, India, pp. 14-23, 2013.

[25] S. H. Lim, H. S. Choi, D. C. Chung, Y. H. Jeong, Y. H. Han, and B S. Han, "Fault Current Limiter Characteristics of Resistive-Type 
SFCL using a Transformer," IEEE Transactions on Applied Superconductivity, vol. 15, pp. 2055-2058, 2005.

[26] P. V. Rama, and M. Swathi, "Superconducting Fault Current Limiter in DC Systems with MLI Fed to IM," ITSI Transactions on Electrical and Electronics Engineering, vol. 3, pp. 25-28, 2015.

[27] M. Priyanka, and P. J. Shah, "Designing and Analysis of Power System with SFCL Module," International Journal on Recent and Innovation Trends in Computing and Communication, vol. 3, pp. 7882,2015

[28] G. Didier, C. H. Bonnard, T. Lubin, and J. Levegne, "Comparison between inductive and resistive SFCL in terms of current limitation and power system transient stability," Electric Power System Research, vol. 125, pp. 150-158, 2015.

[29] C. V. Chaudhary, G. K. Mahajan, and A. P. Chaudhary, "A Comprehensive review on Superconducting fault current limiters in Electrical Utility Network," International Journal of Emerging Trends in Science and Technology, vol. 2, pp. 2466-2479, 2015.

[30] R. Pawar, and P. Chavan, "Minimizing of Fault Current using SFCL technology," International Journal of Engineering Development and Research, vol. 5, pp. 1261-1267, 2017.

[31] Q. Yang, S. L. Blond, F. Liang, M. Zhang, W. Yuan, and J. Li, "Design and application of Superconducting Fault Current Limiter in a Multi-Terminal HVDC System," IEEE Transactions on Applied Superconductivity, vol. 27, pp. 1-5, 2017.

[32] R. K. Rojin, "A Review of Power quality problems and solutions in Electrical Power System," International Journal of Advanced Research in Electrical, Electronics and Instrumentation Engineering, vol. 2, pp. 5605-5614, 2013.

[33] P. Mahajan, P. J. Shah, and R. Saxena, "Analysis of smart grid with superconducting fault current limiters," International Journal of Science, Spirituality, Business and Technology, vol. 3, pp. 87-91, 2015.

[34] S. M. Blair, C. D. Booth, and G. M. Burt, "Current-time characteristics of resistive superconducting fault current limiters," IEEE Transactions on Applied Superconductivity, vol. 22, pp 5600205-5600205, 2012

[35] A. Mohamed, and A. M. Emad, "Enhancement of Multi-Machine power system Transient stability using superconducting fault curren limiters with YBCO and Bi-2212," World Congress on Power and Energy Engineering, Cairo, Egypt, 2012.

[36] M. A. Mohamed, and A. M. Emad, "Enhancement of Multi-Machine Power System Transient Stability using Superconducting Fault Current Limiters with YBCO and Bi-2212," International Journal on Power Engineering and Energy, vol. 5, pp. 418-423, 2014.

[37] F. Tariverdi, and A. Doroudi, "Selection of Resistive and Inductive Superconductor Fault Current Limiters location considering system transient stability," Journal of Electric power and Energy Conversion Systems, vol. 1, pp. 72-78, 2016.

[38] K. Masoud, and B. Mehdi, "Transient Stability Improvement of Power Systems by optimal sizing and allocation of Resistive Superconducting Fault Current Limiters using Particle Swarm Optimization," Advanced Energy: An International Journal (AEIJ), vol. 1: pp. 11-27, 2014

[39] I. K. Okakwu, and E. A. Ogujor, "Enhancement of transient stability of the Nigeria $330 \mathrm{kV}$ transmission network using Fault Curren Limiter," Journal of Power and Energy Engineering, vol. 5, pp. 92103, 2017.

[40] S. L. Jerika, A. B. Carlos, Y. S. Carlos, A. Silhanek, and V. Moshchalkov, "Electrical and Magnetic Characterization of BSCCO and YBCO HTS Tapes for Fault Current Limiter application," IEEE transactions on Applied Superconductivity, vol. 21, pp. 3398-3402, 2011.

[41] H. Raza, S. Muhammad, and B. Syed, "Protection and Coordination using Superconducting Fault Current Limiters in Micro-grids,' Journal of the Korean Institute of Illuminating and Electrical Installation Engineers, vol. 10, pp. 26-36, 2017.

[42] M. Panneerselvan, P. Prakasan, and J. K. Chithra, "Implementation of an Effective Fault Current Limiter for 1.5mw DFIG in Wind Power System," International Journal of Engineering and Technology, vol. 6, pp. 627-635, 2014

[43] A. Biswas, M. E. Khan, and U. Sarker, "Transient Stability Improvement of a Conventional Power System by Superconducting Fault Current Limiter," Global Journal of Researches in Engineering, vol. 13, pp. 1-6, 2013.

[44] H. Hooshyar, H. Heydari, M. Savaghebi, and R. Sharifi, "Resistor type Superconducting Fault Current Limiter: Optimum Shun resistance determination to enhance power system transient stability,' IEEJ Transactions on Power and Energy vol. 2, pp. 299-308, 2009.

[45] B. C. Sung, and J. Park, "A Study on Optimization of Resistive SFCL for Multi-Machine Power System using Eigenvalue Analysis," Journal of International Council on Electrical Engineering, vol. 4, pp. $167-172,2014$

I. K. Okakwu graduated from Ambrose Alli University, Ekpoma (Nigeria) in 2008. He received M. Sc. degree from the University of Lagos in 2012 all in Electrical/Electronic Engineering. He is currently pursuing a $\mathrm{Ph}$. D. degree in Electrical/Electronic Engineering, University of Benin, Nigeria. His area of interest include power systems stability and control, electrical machines, power systems reliability, economic dispatch, FACTS and its applications, deregulation.

P. E. Orukpe is a Professor with the Department of Electrical/Electronic Engineering, University of Benin. She holds a Ph. D. degree in Control Engineering and M. Sc. in Control Systems from Imperial College London. She also holds M. Eng. in Electronics and Telecommunications and B. Eng. in Electrical/Electronic Engineering from University of Benin, Nigeria. She was awarded the Commonwealth Scholarship for her Ph. D. and M. Sc. degrees. Her research interest includes model predictive control, application of control to biomedical science, numerical analysis, optimization techniques, communications and energy policies

E. A. Ogujor is a Professor/Consultant in the Department of Electrical/Electronic Engineering, University of Benin, Benin City, Edo State, Nigeria and currently a rector at Delta State Polytechnic, Oghara with over twelve (12) years of teaching and research experience. He obtained B. Eng. (Electrical/Electronic Engineering) 1997, M. Eng. (2000) and Ph. D. (2006) in Electric Power Systems and Machines Engineering from University of Benin. He has published over thirty (30) research papers in both national and international peer reviewed journals. His research interest includes: Reliability/Protection of Electric Power Systems, NonConventional Energy Systems, Power System Planning and Vegetation Management in Electric Power Systems. He is a member of Institute of Electrical/Electronic Engineering (IEEE) USA, Nigerian Society of Engineers (NSE), and Council for the Regulation of Engineering in Nigeria (COREN). 